\title{
Single access retroperitoneoscopic adrenalectomy: initial experience
}

\author{
Virgilijus Beiša, Edvinas Kildušis, Kęstutis Strupas \\ Vilnius University Hospital Santariskiu Clinics, Center of Abdominal Surgery, Lithuania
}

Videosurgery and Other Miniinvasive Techniques 2012; 7 (1): 45-49 DOI: 10.5114/wiitm.2011.25640

\begin{abstract}
Today, endoscopic adrenalectomy has become a gold standard in endocrine surgery. To minimize the morbidity and improve cosmesis, single access retroperitoneoscopic adrenalectomy (SARA) has been developed as an alternative to traditional multiport laparoscopy and single port access (SPA) surgery, potentially exploiting even more the already proven benefits of minimally invasive surgery. We applied the SARA technique to adrenalectomy using the posterior retroperitoneal approach. The aim is to highlight the current situation regarding the feasibility and safety of single access retroperitoneoscopic adrenalectomy and to present our initial experience. Between October 2010 and February 2011, a 74-year-old woman (body mass index (BMI) - $31 \mathrm{~kg} / \mathrm{m}^{2}$ ) with pheochromocytoma (1.2 $\mathrm{cm}$ in size) and 3 women, aged 45, 46 and 66 years $\left(B M I-27,32,33 \mathrm{~kg} / \mathrm{m}^{2}\right)$, respectively, and all diagnosed with Conn's adeno$\mathrm{ma}$ (from $1.2 \mathrm{~cm}$ to $2.0 \mathrm{~cm}$ in size), underwent single access retroperitoneoscopic adrenalectomies. Operations were performed using conventional laparoscopic (STORZ) equipment. No conversions to the open or conventional retroperitoneal approach were necessary. There were no perioperative or postoperative complications. Operating time ranged from 60 min to $80 \mathrm{~min}$. All patients left the hospital 2 days after surgery. The single access retroperitoneoscopic technique has been successfully applied to adrenalectomy as an available alternative to multiport laparoendoscopic adrenalectomy and single port access surgery. Exposure, visualization and dissection are the same as in retroperitoneal endoscopic adrenalectomy. The SARA surgery offers patient benefits such as faster convalescence, decreased postoperative scarring, better cosmetic effect and financial benefit.
\end{abstract}

Key words: endocrine surgery, adrenalectomy, retroperitoneoscopy, single access.

\section{Introduction}

In the past two decades, laparoscopic surgery has almost replaced open surgery in most types of abdominal surgery, including adrenalectomies, for which it has become the method of choice in most cases [1-5]. The evolution of surgery today is toward less and less invasiveness [6], stimulated by the concept of natural orifice transluminal endoscopic surgery (NOTES) [7]. Our actual concept of SARA may supersede NOTES in adrenal surgery [1].
Since the first descriptions of endoscopic adrenal removals in 1992 [8, 9], minimally invasive adrenalectomy has become the gold standard in adrenal surgery $[10,11]$. In 1994, minimally invasive adrenalectomy started to be performed using the posterior retroperitoneoscopic approach routinely using three ports [12]. Recently, we described a modification as a single-access procedure. This surgical technique may offer further progress in minimizing perioperative morbidity and increasing cosmesis [1]. 
Traditional laparoscopic techniques for adrenalectomy usually need several trocars for retraction of neighbouring visceral organs to expose the adrenal gland in the retroperitoneum. The posterior retroperitoneoscopic approach is thought to be the most promising method to perform single access surgery of the adrenal glands as it offers a direct way to the retroperitoneal organs [1]. This feature has made single access retroperitoneoscopic adrenalectomy a perfect solution for adrenal tumours.

The purpose of this article is to report on our first 4 cases of adrenalectomy in which the SARA technique was applied and to highlight the current situation regarding the feasibility and safety of performing single access retroperitoneoscopic adrenalectomy using conventional laparoscopic equipment in the Center of Abdominal Surgery at Vilnius University Hospital Santariskiu Clinics.

\section{Case report}

In the Center of Abdominal Surgery at Vilnius University Hospital Santariskiu Clinics between October, 2010 and February, 2011, four single access retroperitoneoscopic adrenalectomies were performed using conventional laparoscopic (STORZ) equipment. The patients were 45, 46, 66 and 74 year old women with body mass index (BMI) of 27, 32, 33, $31 \mathrm{~kg} / \mathrm{m}^{2}$ respectively and who complained of high blood pressure.

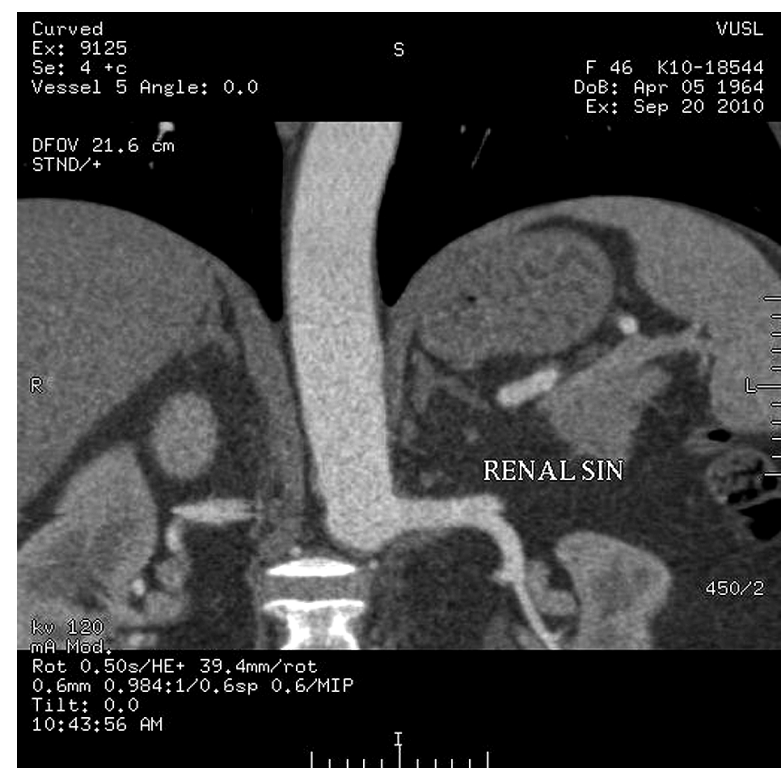

Figure 1. Computed tomography views of adrenal gland
All patients with adrenal gland tumours were thoroughly examined by an endocrinologist using ultrasound and computed tomography (CT) scans. Blood and urine levels of electrolytes and catecholamines and blood levels of aldosterone and cortisol were evaluated in all patients.

One patient had an increased level of catecholamines (adrenaline $300 \mathrm{ng} / \mathrm{l}$ and noradrenaline $900 \mathrm{ng} / \mathrm{l})$ in the blood; the other 3 had increased levels of aldosterone in the blood (320 ng/l, $1126 \mathrm{ng} / \mathrm{l}$, $694 \mathrm{ng} / \mathrm{l})$. All patients underwent an abdominal CT scan: in the patient with increased blood levels of catecholamine $12 \mathrm{~mm}$ pheochromocytoma in the right adrenal gland was found (Figure 1). Patients with increased aldosterone showed $12 \mathrm{~mm}, 12 \mathrm{~mm}$ and $20 \mathrm{~mm}$ tumours in diameter in the right adrenal glands (Conn's adenomas).

After an explanation of the SARA method, all the patients gave their informed consent. Patients' data, operating time, estimated blood loss, perioperative and postoperative complications and outcomes were registered.

\section{Surgical technique}

After induction of general anaesthesia, the patient is placed in the prone jack-knife position (Figure 2). Following a $2.5 \mathrm{~cm}$ transverse skin incision just beneath the tip of the $12^{\text {th }}$ rib (Figure 3 ), the

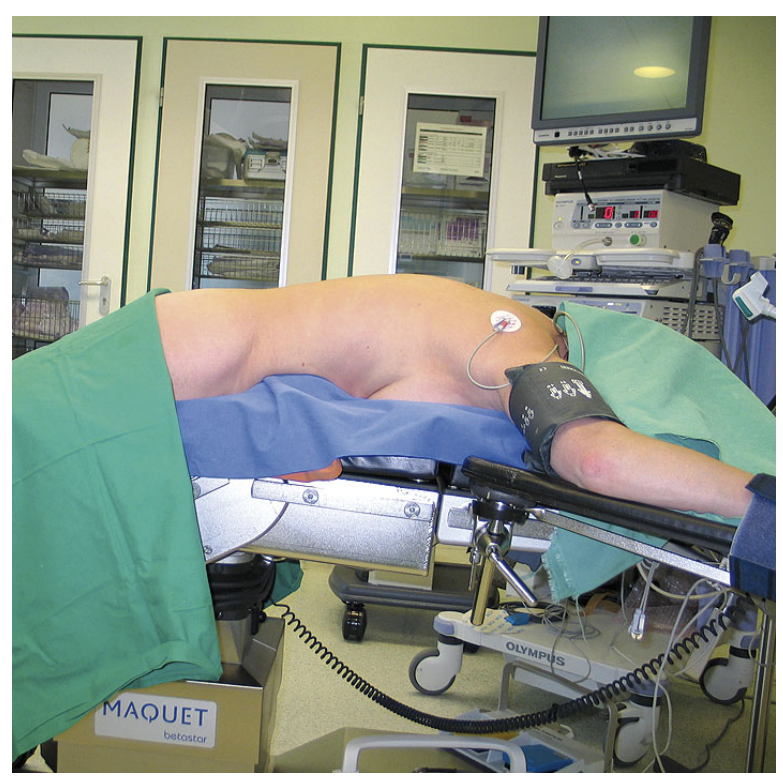

Figure 2. Prone jack-knife position 


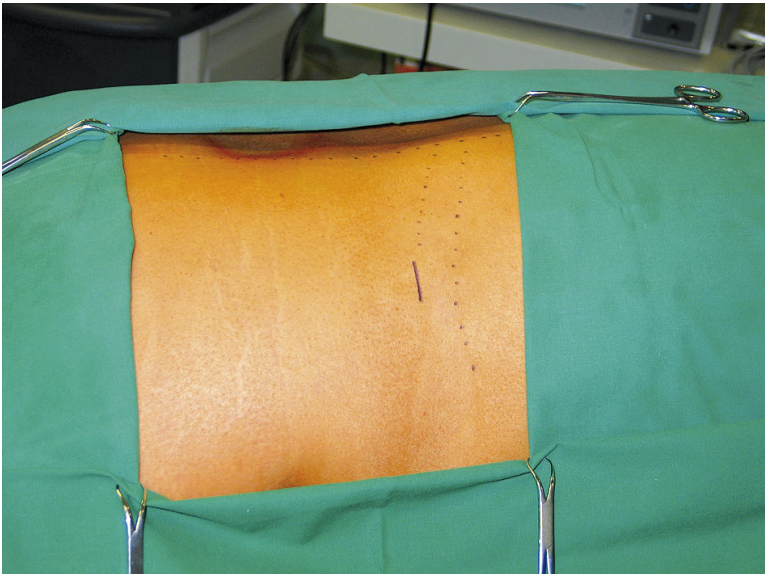

Figure 3. Marked line of skin incision

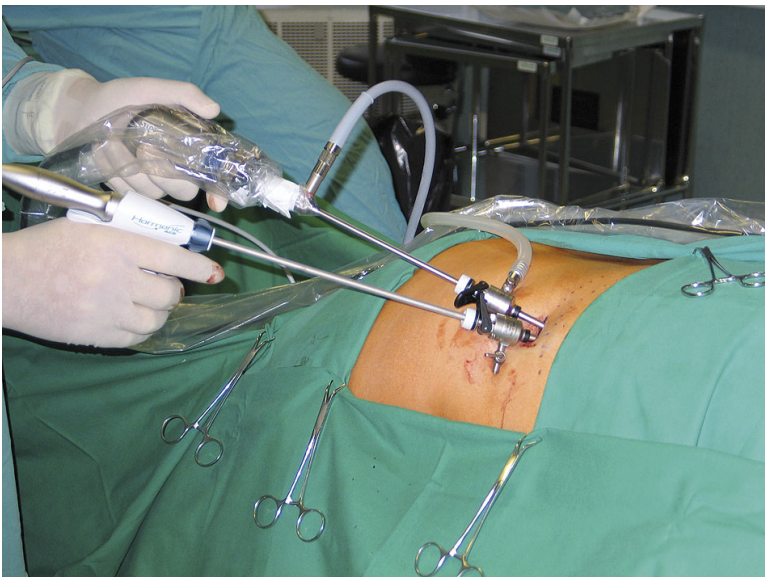

Figure 5. Single access retroperitoneoscopic adrenalectomy. Camera and bipolar scissors are introduced through one incision

retroperitoneum is entered with a $10 \mathrm{~mm}$ cutting optical trocar under endoscopic view (Figure 4). Retroperitoneoscopy is performed by a $10 \mathrm{~mm} 30^{\circ}$ endoscope (Karl Storz Endoskope, Tuttlingen, Germany). The endoscope itself allows step-by-step creation of the retroperitoneal space by disruption of Gerota's fascia and by pushing the retroperitoneal fatty tissue bluntly downwards [1]. The capnoretroperitoneum is created by a carbon dioxide pressure of $20 \mathrm{mmHg}$.

After extraction of the $10 \mathrm{~mm}$ trocar, through the same incision two $5 \mathrm{~mm}$ trocars for the introduction of conventional laparoscopic instruments $\left(5 \mathrm{~mm} 30^{\circ}\right.$ endoscope and $5 \mathrm{~mm}$ ultrasonic dissector) were placed (Figure 5). The dissection is completely performed in a single hand technique. The non-domi-

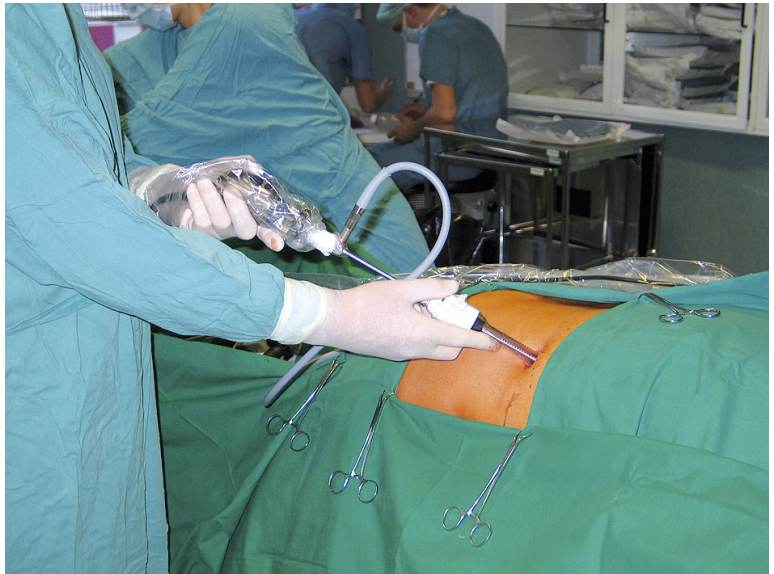

Figure 4. Trocar under endoscopic view

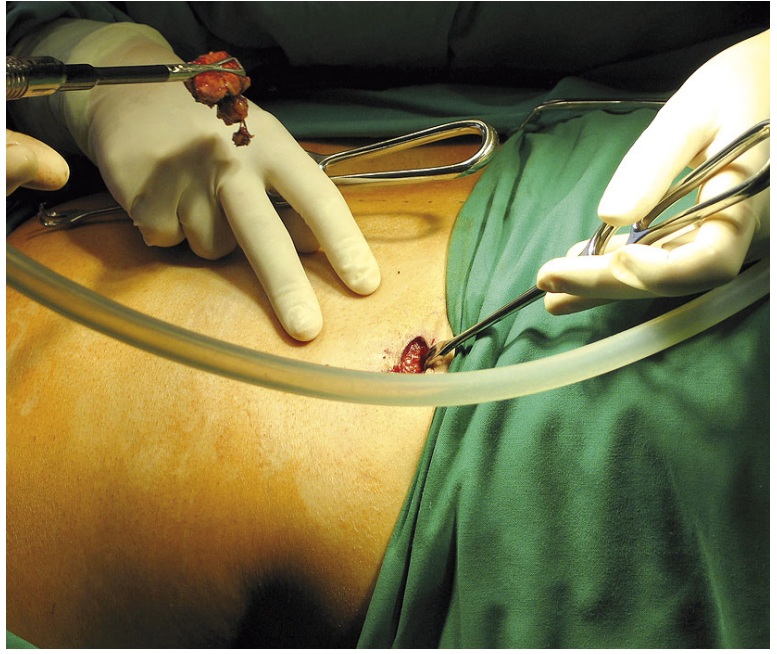

Figure 6. Extraction of the specimen

nant hand holds the camera. After exposing the adrenal gland, the adrenal vein was dissected with the bipolar scissors (LigaSure ${ }^{\circledR}$, Covidian, Neustadt, Germany).

One $5 \mathrm{~mm}$ trocar was pulled out, leaving the introducer, which helps to re-insert the $10 \mathrm{~mm}$ trocar. Through it with Bebcock forceps ( $10 \mathrm{~mm}$ in diameter) the gland is captured and the specimen is extracted (Figure 6). No drain was inserted and the incision was closed subcutaneously (Figure 7).

No conversions to the open or conventional retroperitoneal approach were necessary. Mean operating time was $70 \mathrm{~min}$ (range: $60-80 \mathrm{~min}$ ). Blood loss was insignificant (Table I). There were no preoperative or postoperative complications. None of the patients received pain medication postoperatively 


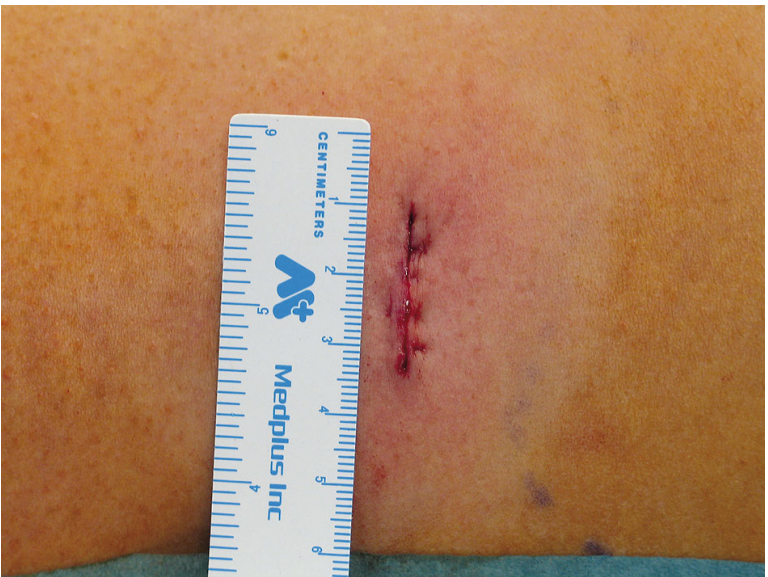

Figure 7. Result after single access retroperitoneoscopic adrenalectomy operation

after more than $10 \mathrm{~h}$. Patients were discharged 2 days after adrenalectomy.

\section{Discussion}

Over the last decade, standard laparoscopic and endoscopic retroperitoneal adrenalectomies have been the most popular [13]. Single access retroperitoneoscopic adrenalectomy with single port surgery represents the next generation in surgery. It uses a single skin incision, often concealed, to perform procedures with minimal scarring and reducing the trauma of surgical access, respecting the basic principles of adrenalectomy. The few published reports suggest a modest advantage for SARA surgery over standard laparoscopy, retroperitoneoscopy or SPA in terms of convalescence, postoperative pain, cosmetic effect or financial benefit $[1,7]$.

Attempts to perform adrenal surgery through a single incision began with a report by Kageyama et al. in 2004 [14] and later Hirano et al. in 2005 [15]. The latter investigators used a specialized resectoscope

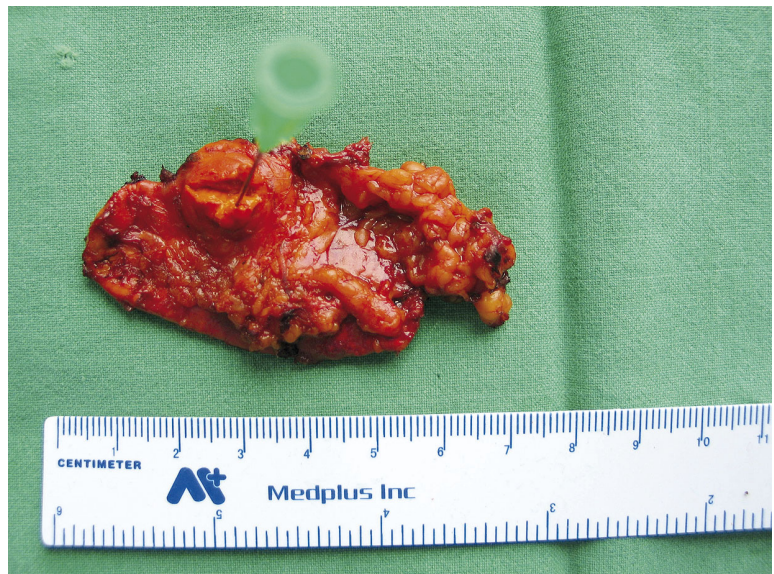

Figure 8. Adrenal gland tumour (opened and marked with needle)

tube with $4 \mathrm{~cm}$ diameter and standard laparoscopic instruments to perform a retroperitoneoscopic adrenalectomy without insufflation. Compared to SARA, feasibility, safety and cosmesis seem to be significantly poorer [1].

In 1994, minimally invasive adrenalectomy by the posterior approach was started by Walz et al. [12]. Now Walz and Alesina have developed and published the single-access retroperitoneoscopic adrenalectomy (SARA) method without any device as an access platform for placing instruments into the retroperitoneum [1]. The only generally accepted contraindication is obvious malignoma $[1,7]$.

If during operation with the TriPort it is necessary to convert to retroperitoneal endoscopic surgery, when three trocars are used, the TriPort remains unused. It increases the operation's cost. The SARA method does not require the expensive TriPort, and it is always possible to convert SARA into retroperitoneal endoscopic surgery with 3 trocars.

The cosmetic effect of SARA compared with the 3-trocar method is unquestionably better. The oper-

Table I. Characteristics of patients undergoing single access retroperitoneoscopic adrenalectomy

\begin{tabular}{|lccccccc|}
\hline Patient & Age $/ \mathrm{sex}$ & BMI $\left[\mathrm{kg} / \mathrm{m}^{2}\right]$ & Site & Size $[\mathrm{cm}]$ & Diagnosis & Operative time [min] & Blood loss [ml] \\
\hline 1 & $46 / \mathrm{F}$ & 32 & $\mathrm{R}$ & 1.2 & Conn's adenoma & 80 & 10 \\
\hline 2 & $74 / \mathrm{F}$ & 31 & $\mathrm{R}$ & 1.2 & Pheochromocytoma & 60 & 20 \\
\hline 3 & $45 / \mathrm{F}$ & 27 & $\mathrm{R}$ & 1.2 & Conn's adenoma & 80 & 20 \\
\hline 4 & $66 / \mathrm{F}$ & 33 & $\mathrm{R}$ & 2.0 & Conn's adenoma & 80 & 5 \\
\hline
\end{tabular}


ation is limited to patients with tumours up to $2.5 \mathrm{~cm}$ in size, because only then is it possible to extract the adrenal gland in one piece, through the $2.5 \mathrm{~cm}$ incision. If the size of the specimen exceeds the size of the skin incision, the tissue needs to be morcellated [1].

The paucity of published studies makes it difficult to draw conclusions regarding complication rates with SARA adrenalectomy. Future studies should elucidate whether an additional benefit to this technique exists other than a favourable cosmetic result or financial benefit. These studies will probably require more sensitive metrics and longer postoperative follow-up to detect any existing differences.

\section{Conclusions}

Single access retroperitoneoscopic adrenalectomy can be done safely by using conventional laparoscopic instruments.

\section{References}

1. Walz MK, Alesina PF. Single access retroperitoneoscopic adrenalectomy (SARA) - one step beyond in endocrine surgery. Langenbecks Arch Surg 2009; 394: 447-50.

2. Łosin M, Czauderna P, Gołębiewski A, et al. Single incision laparoscopic adrenalectomy - initial experience. Videosurgery and Other Miniinvasive Techniques 2010; 5: 104-6.

3. Myśliwiec P, Dadan J, Łukaszewicz J. Two tumours of the right adrenal gland treated videoscopically by the posterior retroperitoneal approach. Videosurgery and Other Miniinvasive Techniques 2009; 4: 126-30.

4. Toutounchi S, Cieśla W, Krajewska E. Laparoscopic enucleation of a single adrenal tumour in a patient suffering from primary hyperaldosteronism. Videosurgery and Other Miniinvasive Techniques 2007; 2: 164-7.

5. Otto M, Dzwonkowski J, Ciaćcka T. Laparoscopic adrenalectomy in elderly patients. Videosurgery and Other Miniinvasive Techniques 2006; 2: 54-8.

6. Rattner D, Kaloo A. ASGE/SAGES working group on natural orifice transluminal endoscopic surgery. Surg Endosc 2006; 20: 329.

7. Walz MK, Groeben H, Alesina PF. Single-Access Retroperitoneoscopic Adrenalectomy (SARA) Versus Conventional Retroperitoneoscopic Adrenalectomy (CORA): a case-control study. World J Surg 2010; 34: 1386-90.

8. Gagner M, Lacroix A, Bolte E. Laparoscopic adrenalectomy in Cushing's syndrome and pheochromocytoma. N Engl J Med 1992; 327: 1033.

9. Higashihara E, Tanaka Y, Horie S, et al. A case report of laparoscopic adrenalectomy. Nippon Hinyokika Gakkai Zasshi 1992; 83: 1130-3.

10. Brunt LM. Minimal access adrenal surgery. Surg Endosc 2006; 20: 351-61.
11. Cywiński J, Kuzdak K, Kołomecki K. One-incision approach (SILS) for retroperitoneal videoscopic adrenalectomy. Videosurgery and Other Miniinvasive Techniques 2010; 5: 70-1.

12. Walz MK, Peitgen K, Hoermann R, et al. Posterior retroperitoneoscopy as a new minimally invasive approach for adrenalectomy: results of 30 adrenalectomies in 27 patients. World J Surg 1996; 20: 769-74.

13. Beisa V, Simutis G, Strupas K. Evaluation of two methods of endoscopic adrenalectomy. Zentralbl Chir 2009; 134: 237-41.

14. Kageyama Y, Kihara K, Kobayashi T, et al. Portless endoscopic adrenalectomy via a single minimal incision using a retroperitoneal approach: experience with initial 30 cases. Int J Urol 2004; 11: 693-9.

15. Hirano D, Minei S, Yamaguchi K, et al. Retroperitoneoscopic adrenalectomy for adrenal tumors via a single large port. J Endourol 2005; 19: 788-92. 